\title{
Multinational Corporations and Social Responsibility in Emerging Markets: Opportunities and Challenges for Research and Practice
}

I was honored when Alex Michalos, Editor-in-Chief of the Journal of Business Ethics, invited me to edit a special issue. As a strategy scholar, I wondered how to make the most contribution for the journal and its readers. Amongst the various forces that have been reshaping global competitive landscape, the growing attention on the corporate social responsibility (CSR), without doubt, is one of the most noteworthy. While multinational corporations (MNCs) have come to terms with CSR agenda, the concept of CSR itself remains ambiguous. Although many MNCs have attempted to integrate CSR in their strategic decisions and implementations, few seem to have found a proper balance between their aspirations in CSR and their performance in emerging markets. What is lacking is a better understanding of what exactly is required of today's MNCs to simultaneously generate profits for shareholders and make a positive contribution to the multiple stakeholders in the countries where they conduct business.

For MNCs operating in emerging markets, the fast-growing wealth represents a tremendous opportunity. At the same time, these emerging markets also present huge challenge to the MNCs due to underdeveloped institutional environment, weak public governance, widespread bribery and corruption, lack of regulatory legislations and rules, public transparency, and respect for human rights. How can MNCs better formulate CSR policies and actively implement them in these economies undergoing profound institutional transformation? Obviously, first, it is important to understand the environmental characteristics and how MNCs responded to CSR pressure in these emerging markets.
In the end I have decided to devote to a single topic of profound academic and practical importance, and provide a forum for in-depth knowledge consolidation and forward thinking by scholars from around the world. I chose CSR as the theme, and I chose to focus on the issues arising from MNCs in emerging markets. As these economies gradually undergo fundamental institutional reform and become increasingly integrated into global economy, an improved understanding of CSR issues in these markets has gained added significance for theory and practice. It is my effort and those of all the scholars who have contributed to this collection to help narrow the gap between the importance of CSR among MNCs in emerging markets and the research effort devoted to it.

This collection of articles aims to deepen our comprehension of the economic ethics of MNCs in different emerging markets. Allow me to briefly preview what you will find in this issue. The first featured article by Xiaohua Yang and Cheryl Rivers (Antecedents of CSR Practices in MNCs' Subsidiaries: A Stakeholder and Institutional Perspective) examines antecedents of CSR in MNC subsidiaries. Drawing from the stakeholder and institutional theories that identify internal and external pressures for legitimacy in MNC subsidiaries, the authors integrate international business and CSR literatures and present a model depicting CSR practices in MNCs' subsidiaries. They propose that MNCs' subsidiaries will be likely to adapt to local practices to legitimize themselves if they operate in host countries with different institutional environments and demanding stakeholders. To examine the same issue (Institutional 
Structure and Firm Social Performance in Transitional Economies: Evidence of Multinational Corporations in China), Justin Tan uses mixed methods, including analyses of corporate documents and media reports, as well as interviews with a range of actors from the field to construct an understanding of legitimate CSR practices to examine the explanatory factors leading MNCs, otherwise recognized for accountability and integrity in their home markets, to employ inconsistent or negligent practices in their overseas subsidiaries. Preliminary findings reveal that discrepancies exist in how MNCs' overseas subsidiaries perform in CSR in home countries versus in host countries. While MNCs do have much to improve, the institutional environment in the emerging market, including the legal framework and the ethical culture, also needs to be improved by the host country governments, the industry associations, and local firms. Meanwhile, media interest and journalists, NGOs, third-party monitors, industry stakeholders as well as consumer advocacy groups can raise the visibility of MNC's contradictory practices between their origin nations and countries with emerging economies and offer the pressures and incentives for MNCs to amend their ethical shortcomings.

The article by Terry Beckman, Alison Colwell, and Peggy Cunningham (The Emergence of Corporate Social Responsibility in Chile: The Importance of Authenticity and Social Networks) attempts to examine how and why CSR emerged in less developed countries. They collected and analyzed data from multiple sources from Chile and discovered that MNCs and non-governmental organizations (NGOs) are key factors promoting CSR in Chile.

In the next article, Gabriel Eweje examines various ethical issues relating to labor relations and trade unions in Nigeria, South Africa, and Zambia (Labour Relations and Ethical Dilemma of Extractive MNEs in Nigeria, South Africa and Zambia: 1950-2000). The argument advanced in his study is that the MNEs operating in the extractive industries of Africa will have to improve their relations with their local employees to bridge the legitimacy gaps that exist. Also set in Nigeria, in his article titled Corporate Social Responsibility in Transnational Spaces: Exploring Influences of Varieties of Capitalism on Expressions of Corporate Codes of Conduct in Nigeria, Kenneth Amaeshi explores the home country influences of MNCs on their CSR practices when they operate outside their national/regional institutional contexts. The study examines seven MNCs operating in the oil and gas sector of the Nigerian economy. The study concludes that the corporate codes of conduct of these MNCs operating in Nigeria reflect the characteristics of their home countries' model of capitalism, albeit with certain degree of modifications.

Finally, the article by Burkard Eberlein and Dirk Matten (Business Responses to Climate Change Regulation in Canada and Germany - Lessons for MNCs from Emerging Economies) offers a novel mapping of the complex relationship between business ethics and regulation by suggesting five distinct ways in which business ethics and regulation may intersect. The framework is applied to a comparative case study of business responses to climate change regulation in Canada and Germany. Both countries represent distinctly different approaches which yield significant lessons for emerging economies. They also analyze the specific role of large MNCs in this process.

Overall, the set of articles summarize past efforts, introduce new perspectives, provide new empirical insights, and define future research needs on CSR research in a unique context. As the readers will find, individually, each of these articles perhaps has only revealed the tip of a huge iceberg of complexities and challenges arising in different emerging markets, but collectively, the special issue presents a set of compelling issues faced by scholars, policy makers, and managers in MNCs. A hallmark of provocative research is that in addition to offering explanations to the relevant questions we are facing, it also raises more questions for future research. I hope this special issue will inspire other scholars to share our curiosity and generate the kind of dialogue necessary to furthering our understanding in this topic of major theoretical and practical importance.

On a personal note, I wish to express my gratitude to the large number of scholars who graciously and generously gave their time to offer developmental reviews to authors, which has improved the overall quality of the articles. I am particularly grateful to all the authors who have shared their knowledge and experience with us, and allowed us to have their works put forward for possible challenge by their 
peers. They have all contributed to the discussion of this important theme, whether or not their articles are eventually included in this small collection. Their hard work and diligence has provided a set of articles that I am proud to present to you.
Schulich School of Business, York University, Toronto, ON M3J 1P3, Canada

E-mail: jtan@schulich.yorku.ca 